\title{
Sexual Differentiation of the Surge Mode of Gonadotropin Secretion: Prenatal Androgens Abolish the Gonadotropin-Releasing Hormone Surge in the Sheep'
}

\author{
Cristina G. Herbosa ${ }^{2}$, Geoffrey E. Dahl ${ }^{3}$, Neil P. Evans ${ }^{4}$, Juanita Pelt, Ruth I. Wood ${ }^{5}$, and Douglas L. Foster \\ Reproductive Sciences Program and the Departments of Biology, Physiology and Obstetrics and Gynecology, University of Michigan, \\ Ann Arbor, Ml 48109-0404, USA.
}

Key words: LHRH, luteinizing hormone, steroids, GnRH, testosterone.

\begin{abstract}
In sheep, the surge mode of gonadotropin secretion is sexually differentiated, i.e. the LH surge is present in the female, but not in the male. The present study tested the hypothesis that sexual differentiation of the LH surge mechanism reflects a sex difference in the pattern of $\mathrm{GnRH}$, and that prenatal androgens abolish the surge mode of GnRH secretion. We monitored the pattern of GnRH secretion in pituitary portal blood after acute treatment with estradiol in gonadectomized postpubertal males $(n=6)$, females $(n=6)$, and androgenized females (exposed prenatally to testosterone from day 30-90 in gestation, $n=7$ ). Four capsules, each containing a 30-mm column of estradiol were implanted s.c. into each lamb to produce high physiologic concentrations of the hormone. Beginning $7 \mathrm{~h}$ later, portal and peripheral blood samples were collected hourly for $48 \mathrm{~h}$ for measurement of GnRH and LH, respectively. All females exhibited a GnRH surge beginning $13.0 \pm 0.4 \mathrm{~h}$ after estradiol treatment; this was accompanied by an LH surge. By contrast, only one male produced a small surge in GnRH (1.7 pg/min) with a latency of $32 \mathrm{~h}$; a corresponding increase in LH occurred in this male. Likewise, among the androgenized females, only one exhibited GnRH and LH surges which began at about $22 \mathrm{~h}$ after estradiol treatment. Some of the androgenized females had sporadic increases in GnRH which were of lower amplitude than in the control females, and were unaccompanied by rises in LH. These findings provide the first direct evidence that the sex difference in the surge mode of LH secretion results from the sexual differentiation of the pattern of $\mathrm{GnRH}$ release. The study also suggests that androgens during prenatal development abolish the GnRH surge and subsequently, the generation of the LH surge.
\end{abstract}

Pituitary gonadotropins are released in both a tonic and a surge mode of secretion. Whereas the tonic mode is under the inhibitory control of gonadal steroids, the surge mode is activated by the stimulatory feedback action of estradiol. The tonic mode of secretion is operative in both sexes, but in some species including the rat $(1,2)$, guinea pig (3), hamster (4) and sheep (5), the surge is absent in males. This sex difference in the surge mode of secretion has been well-studied, particularly in the rat, and has been an area of considerable interest for some time. That testicular androgens in the neonatal rat organize both the neuroendocrine regulation of gonadotropin secretion and sexual behavior in the adult is firmly established (see 6 , for review). When male rats are castrated within the first few days after birth, the surge mode of gonadotropin secretion is present (7) which can induce cyclical changes in vaginal grafts $(8)$ and the formation of corpora lutea in ovarian grafts $(8,9)$. Neonatal testosterone treatment abolishes the surge mode of secretion in castrated males (9). Similarly in females, exposure to androgens in the first few days of life also abolishes the surge (9-11).

Our previous study in the adult ram determined that the preovulatory surge mechanism is neither functional nor normally inducible by the administration of increased doses of estradiol (5) which are effective in the ewe. Early studies on sexual differentiation of neuroendocrine function in the sheep by Short (12) and Clarke et al. $(13,14)$ determined that the sex difference in the ability to generate the surge is due to the organizing action of testosterone during prenatal development. This finding has been extended by recent studies by our laboratory with prenatally androgenized female lambs (15-17).

The inability of the male to produce the LH surge may stem from the absence of a stimulatory feedback mechanism centrally. Hence, it is possible that in this sex, a GnRH surge does not occur to induce a massive discharge of LH from the pituitary.

\footnotetext{
${ }^{1}$ Preliminary report of this work was presented at the 24th Annual Meeting of the Society for Neuroscience, 1994.

${ }^{2}$ Present address: Department of Obstetrics and Gynecology, The Ohio State University, Columbus, OH 43210-1228, USA.

${ }^{3}$ Present address: Department of Animal Sciences, University of Maryland, College Park, MD 20742-2311, USA.

${ }^{4}$ Present address: Babraham Institute, Babraham Hall, Babraham, Cambridge CB2 4AT, UK.

${ }^{5}$ Present address: Department of Obstetrics and Gynecology, Yale University School of Medicine, New Haven, CT 06520-8063, USA.

Correspondence to: Douglas L. Foster, Room 1101, 300 North Ingalls Building, University of Michigan, Ann Arbor, MI 48109-0404, USA.
} 
Alternatively, it is possible that the GnRH surge mechanism is functional in the male, but the pituitary fails to respond. In the present study, we examined the former hypothesis by characterizing the pattern of $\mathrm{GnRH}$ secretion into the pituitary portal vasculature of males and females in response to acute estradiol stimulation. Methodology for the characterization of the pattern of GnRH secretion in sheep has been well developed (18), and we have recently adapted this for use in the smaller lamb (19). We also tested the hypothesis that a sex difference in the pattern of $\mathrm{GnRH}$ secretion during the surge is established by the action of testicular androgens during prenatal development. Our approach was to examine the pattern of $\mathrm{GnRH}$ in female lambs that have been exposed to androgens during a critical period of development in utero (15-17).

\section{Results}

\section{Females}

Fig. 1 illustrates GnRH and LH surge patterns in all six females; Table 1 summarizes characteristics of these surges. The GnRH surge began $13.0 \pm 0.4 \mathrm{~h}($ mean $\pm S E M)$ after insertion of estradiol implants, and all $\mathrm{GnRH}$ surges were accompanied by an $\mathrm{LH}$ surge beginning at the same time $(12.5 \pm 0.8 \mathrm{~h}, \mathrm{P}=0.5)$. The time to peak concentration from surge onset for the $\operatorname{GnRH}(5.8 \pm 2.0 \mathrm{~h})$

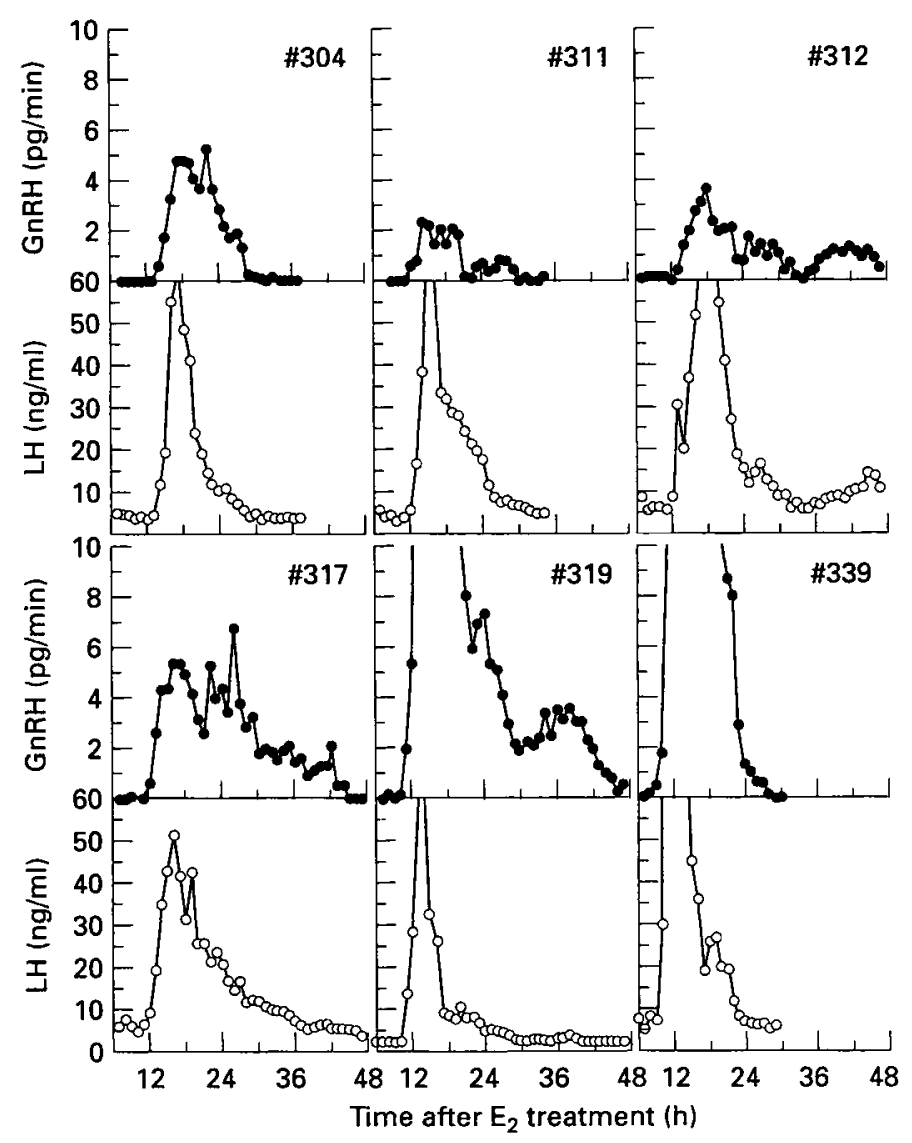

Fig. 1. GnRH (top) and LH (bottom) secretory patterns during the surge in females. All females $(n=6)$ exhibited a sustained increase in GnRH and $\mathrm{LH}$ in response to increased estradiol concentrations. and $\mathrm{LH}(4.0 \pm 0.6 \mathrm{~h})$ surges was similar $(P=1.1)$. There was no difference between the average duration of the GnRH and LH surges $(P=0.3)$. The mean amplitude of the $G n R H$ surge was $10.8 \pm 4.5 \mathrm{pg} / \mathrm{min}$; that of the $\mathrm{LH}$ surge was $67.8 \pm 16.3 \mathrm{ng} / \mathrm{ml}$. Characteristics of the LH surges were similar to those observed in the same females some five weeks earlier (17), before the installation of the portal sampling device.

\section{Males}

Fig. 2 illustrates patterns of $\mathrm{GnRH}$ and $\mathrm{LH}$ in all six males. In contrast to the females, only one male (\#309) produced a GnRH surge which began much later $(32 \mathrm{~h})$ relative to that in the females (range: $12-14 \mathrm{~h}$ ). This surge, albeit of very low amplitude $(1.7 \mathrm{pg} / \mathrm{min})$, was sufficient to elicit a corresponding LH surge. This LH surge began at the same time $(32 \mathrm{~h})$ as the GnRH surge, and was of a magnitude $(101.8 \mathrm{ng} / \mathrm{ml})$ comparable to that of $\mathrm{LH}$ surges in the females (range: $43-141 \mathrm{ng} / \mathrm{ml}$ ). Surge characteristics in the male are presented in Table 1.

\section{Androgenized females}

All androgenized females had uniform, highly masculinized external genitalia (17). This consisted of a penis situated close to the navel, and an empty scrotum. Upon laparoscopic surgery at 3 weeks of age for ovariectomy, the appearance of the ovaries and uteri was similar to that of the normal females. These observations are consistent with those reported previously (15, $16,20)$.

Fig. 3 illustrates patterns of $\mathrm{GnRH}$ and $\mathrm{LH}$ in all androgenized females. Most lambs did not produce a GnRH surge; rather, in 4 of 7 lambs, GnRH concentrations increased sporadically after estradiol treatment. Only 1 androgenized female (\#392) had a sustained increase in GnRH (amplitude: $4.3 \mathrm{pg} / \mathrm{min}$ ) which was accompanied by an LH surge (amplitude: $18.3 \mathrm{ng} / \mathrm{ml}$ ). The surges in this animal occurred at approximately the same time $(\sim 22 \mathrm{~h}$ after estradiol treatment). Although statistical comparisons between the surges occurring in the androgenized female and the normal females were not possible, we noted that the timing of the surges tended to be later, and the magnitude of the LH surge to be smaller in the androgenized female compared to the normal females. There was no instance wherein $\mathrm{LH}$ increased in the absence of a sustained rise in GnRH. Surge characteristics in the androgenized female are presented in Table 1.

\section{Discussion}

By characterizing the pattern of $\mathrm{GnRH}$ in the pituitary portal circulation, the present study provides the first direct evidence that the sex differences in the generation of the gonadotropin surge originates centrally. In each female examined, there was an unambiguous rise in $\mathrm{GnRH}$ occurring approximately $13 \mathrm{~h}$ after treatment with estradiol; each surge of $\mathrm{GnRH}$ was accompanied by a concomitant rise in LH. This is in marked contrast to the males, wherein only one individual exhibited a sustained elevation in GnRH. Although the rise in GnRH in the single male was relatively small in comparison to those observed in the females, it was effective in eliciting a surge of LH. These observations lead to the conclusion that, with rare exception, the hypothalamic drive that stimulates the $\mathrm{LH}$ surge is generally not present in the male sheep.

Sexual differentiation of the mechanisms controlling the genera- 
TABLE 1. GnRH and LH Surge Characteristics in Females, Males, and Androgenized Females.

GnRH

\begin{tabular}{|c|c|c|c|c|c|c|}
\hline Surge parameter & Females & Males & $\begin{array}{l}\text { Androgenized } \\
\text { females }\end{array}$ & Females & Males & $\begin{array}{l}\text { Androgenized } \\
\text { females }\end{array}$ \\
\hline Incidence* & $100 \%(6 / 6)^{\mathrm{a}}$ & $17 \%(1 / 6)^{b}$ & $14 \%(1 / 7)^{b}$ & $100 \%(6 / 6)^{2}$ & $17 \%(1 / 6)^{b}$ & $14 \%(1 / 7)^{b}$ \\
\hline Onset (h after $E_{2}$ ) & $13.0 \pm 0.4$ & 32 & 23 & $12.5 \pm 0.8$ & 32 & 21 \\
\hline Duration (h) & $16.2 \pm 3.3$ & 6 & 14 & $11.2 \pm 0.7$ & not determined & 11 \\
\hline Amplitude & $10.8 \pm 4.5 \mathrm{pg} / \mathrm{min}$ & $1.7 \mathrm{pg} / \mathrm{min}$ & $4.3 \mathrm{pg} / \mathrm{min}$ & $67.8 \pm 16.3 \mathrm{ng} / \mathrm{ml}$ & $101.8 \mathrm{ng} / \mathrm{ml}$ & $18.3 \mathrm{ng} / \mathrm{ml}$ \\
\hline $\begin{array}{l}\text { Time to Peak } \\
\text { concentration }(h)\end{array}$ & $5.8+2.0$ & . & 11 & $4.2 \pm 0.6$ & -2 & -5 \\
\hline
\end{tabular}

Values are expressed as mean $\pm \mathrm{SE}$. Different superscripts denote statistical significance. ${ }^{*}$ Females $v s$ males $(\mathrm{P}=0.015)$; Females $v s$ androgenized females $(P=0.004)$; Males $v s$ androgenized females $(P=1.000)$.

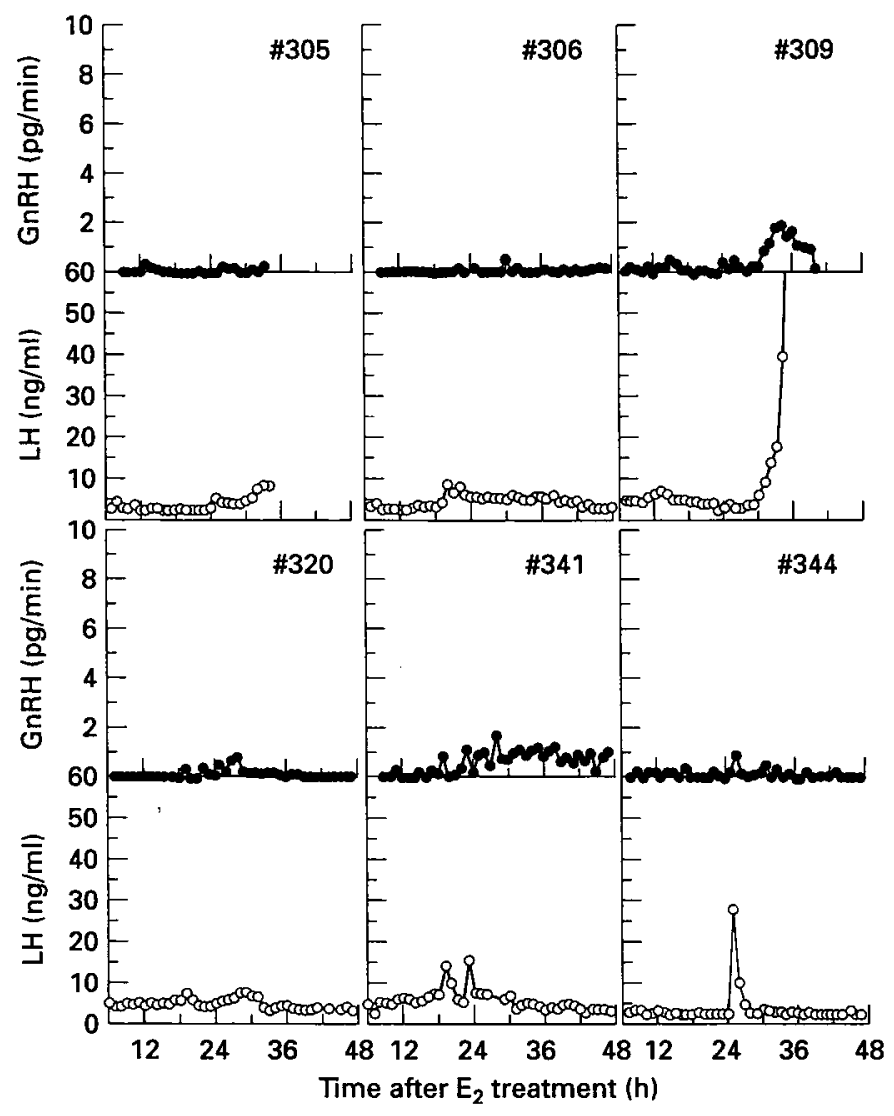

FIG. 2. GnRH (top) and LH (bottom) secretory patterns during the attempt to induce surges in males. Only one male (\#309) exhibited a sustained increase in GnRH and LH in response to increased estradiol concentrations. Peak of the LH surge is off the scale.

tion of the gonadotropin surge in the sheep appears to be intermediate between the mechanisms present in the male rodent and monkey. In male rodents, the surge mode of gonadotropin secretion is completely eliminated $(6,9,21-24)$, while in the castrate male monkey, the $\mathrm{LH}$ surge is inducible by exogenous estrogens (25-28). Although GnRH secretion during the surge has been characterized in the female rat using push-pull perfusion of the medial basal hypothalamus (29) or collection of pituitary stalk blood $(30,31)$, and in the female monkey using push-pull perfusion of the median eminence (32) or collection of cerebrospinal fluid obtained from the third ventricle (33), the pattern of
GnRH during an attempt to induce a surge in males of either of these species has not yet been determined. Thus, it is not known if the GnRH surge is completely obliterated in the case of the male rodent, or is generated in the male monkey. It is clear from the present study that at least in the male sheep, the positive feedback response can be activated occasionally. However, in general, males are largely incapable of producing a massive discharge of $\mathrm{GnRH}$.

The present results provide evidence that the sex difference in the pattern of $\mathrm{GnRH}$ secretion during the surge is likely produced by the presence of testosterone before birth in the sheep. This was evident from the pattern of $\mathrm{GnRH}$ secretion during an attempt to induce a surge in females exposed to testosterone from the 30th-90th day of gestation, the period encompassing sexual differentiation of some neuroendocrine functions in sheep (12-14). We hypothesized that like the males, the GnRH surge in the androgenized females would be abolished by testosterone treatment. Indeed, in only one of seven individuals was a robust positive feedback response to increased estradiol observed. In some of the androgenized females, short-lived increases in GnRH occurred. We hypothesize that because the data generated in the study present cumulative GnRH release over the course of an hour, those increases may represent pooled sporadic and transient pulsatile releases of the hormone, and not sustained neuronal activity. Alternatively, the short-lived increases may be evidence of the existence of a rudimentary positive feedback response which persisted despite prenatal testosterone treatment. It may very well be that although our androgenization paradigm fully masculinized the pattern of tonic gonadotropin secretion in those females (17), complete obliteration of the surge mechanism requires a longer duration, higher levels, or a somewhat different period of exposure to androgens, or perhaps a combination of any of these. Nevertheless, it is important to note here that treatment with testosterone before birth clearly modified the pattern of GnRH secretion in all but one of the androgenized females to the extent that no LH surges were produced.

Our recent study outlined in the companion paper (34), supports our contention that the absence of the LH surge in male and androgenized female sheep results from the lack of sustained activity of GnRH neurons during acute estradiol stimulation. In that study, which examined the expression of c-fos as a marker of cellular activation, approximately $66 \%$ of $\mathrm{GnRH}$ immunoreactive neurons in the preoptic area and hypothalamus in females expressed Fos protein during the LH surge. In contrast, in the same region in males, as well as in androgenized females, very 

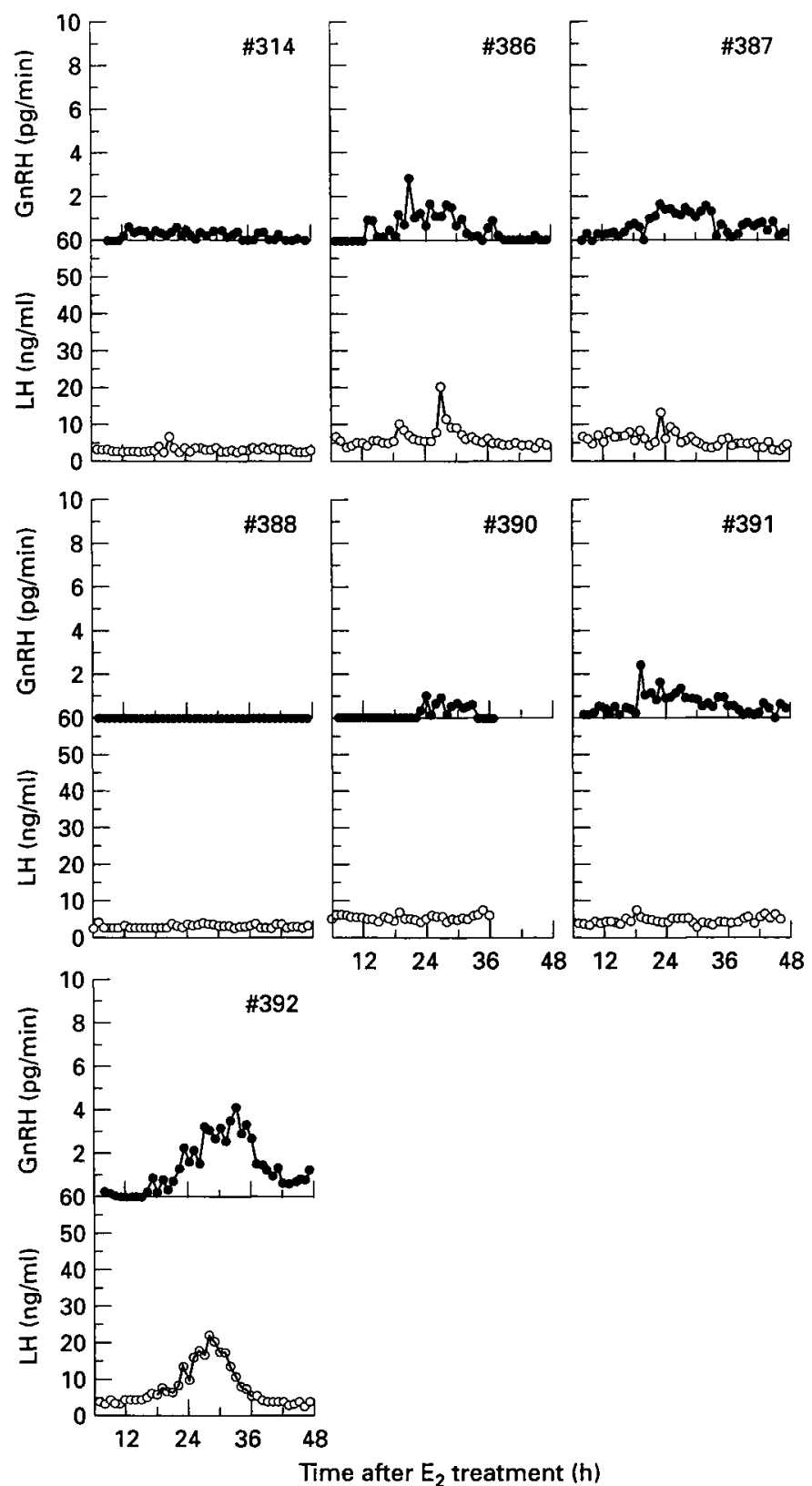

FIG. 3. GnRH (top) and LH (bottom) secretory patterns during the attempt to induce surges in androgenized females. Only one exhibited a sustained increase in both GnRH and $\mathrm{LH}$ in response to increased estradiol concentrations (\#392). Short-lived elevations of GnRH above baseline were observed in some of the lambs.

few GnRH neurons expressed Fos, and these sheep did not produce an LH surge. It is possible that in view of the observations on the single male that produced an increase in GnRH in the present study (\#309, Fig. 2), and the infrequent surges in males in other studies $(5,16)$, activation of GnRH neurons in males may occur occasionally, but after a longer latent period following estradiol stimulation.

Our limited data in the male also suggest that the pituitary response to $\mathrm{GnRH}$ is not sexually differentiated. The relatively small GnRH surge in the single male was effective in eliciting a release in LH of comparable magnitude as those produced by normal females. Our understanding that the pituitary response to GnRH is not sexually differentiated is supported by past findings in the sheep (35), cattle (36) and monkey (37), that administration of the decapeptide in an appropriate pattern to the male can produce an $\mathrm{LH}$ response similar to that in females. While it has been shown that estrogen directly induces the LH surge in hypothalamo-pituitary disconnected adult female sheep (38), and that the LH surge is augmented by GnRH (39), similar studies in the male are lacking. It is therefore possible that the surge mechanism in males (and prenatally androgenized females) has a different threshold of response to steroids compared to females. This remains to be determined.

Currently, the neuronal mechanisms underlying the generation of the GnRH surge are poorly understood for any species, and therefore attempts to elucidate sex differences in those mechanisms are difficult. Because males can exhibit surges occasionally, we postulate that the basic neuronal circuitry for the surge is present in both sexes. Indeed, the GnRH neuron itself is not different between male and female sheep in terms of morphology, number, and distribution (40). However, it is possible that it is the environment of the GnRH neuron which is modified during sexual differentiation, resulting in a positive feedback mechanism that is more difficult to activate in the male. For example, it has been observed in the rhesus monkey that synaptic input to, and degree of glial ensheathment of GnRH neurons are subject to remodelling by gonadal steroids (41). Therefore various neurotransmitter inputs, both inhibitory (e.g. endogenous opioids, dopamine) and stimulatory (e.g. norepinephrine, neuropeptide-Y, excitatory amino acids) to GnRH secretion may be differentially organized by prenatal androgens in the sheep. In the male, this generally results in the uncoupling of GnRH neurons from the positive feedback effects of estradiol.

\section{Materials and methods}

\section{Animals}

Male $(n=6)$ and female $(n=6)$ lambs of predominantly Suffolk breeding were used. They were raised indoors under a natural simulate photoperiod (20), and were fed ad libitum with a diet consisting of alfalfa hay and a commercial pellet ration (Lamb 18, Kent Feed, Inc., Muscatine, IA, USA) containing $18 \%$ protein, supplemented with vitamins and minerals. The lambs grew rapidly and weighed approximately $50 \mathrm{~kg}$ at the time of the experiment, when they were about 41 weeks of age.

To determine if the GnRH surge is abolished by the organizing action of testicular androgens during fetal development, an additional group of female lambs $(n=7)$ was exposed prenatally to androgens. To produce the masculinized female lambs, five pregnant ewes were injected weekly from the 30th to the 90th day in gestation (term: $\sim 150$ days) with testosterone cypionate $(200 \mathrm{mg}$ in $0.5 \mathrm{ml}$ cottonseed oil, im; Sigma Chemical Co., St. Louis, MO, USA). During this broad period in fetal development, sexual differentiation of external genitalia and neuroendocrine function occur $(12-16,20,42)$. The dose and duration of androgen treatment produced uniform, unequivocal, and complete masculinization of the external genitalia in these female lambs $(17,20)$. The androgenized female lambs resulting from this treatment, as well as the other male and female lambs, were all postpubertal at the time of the experiment, as evidenced by their patterns of circulating $\mathrm{LH}(17,20)$.

Gonadectomy and induction of the GnRH/LH surge

The gonadectomized, steroid-replaced model was used. Testes were removed under local lidocaine anesthesia when males were approximately one week of age. Ovaries from normal and androgenized females were removed under acepromazine/ketamine anesthesia $(0.2 \mathrm{mg} / \mathrm{kg}$ and $20 \mathrm{mg} / \mathrm{kg}$ body weight, respectively, i.m.) through a midline abdominal 
incision at 3 weeks of age. To provide constant steroid feedback throughout development, an estradiol implant designed to produce physiologic concentrations of estradiol was inserted s.c. in each lamb at the time of gonadectomy. In this model, sexual maturity is defined by the sustained increase in $\mathrm{LH}$ secretion (43). After the attainment of puberty, the steroid implants were removed for 3 weeks before the surge induction experiment as described below.

To determine if there is a sex difference in the stimulatory feedback response of $\mathrm{GnRH}$ secretion to estradiol, we attempted to activate the LH surge mechanism in males, females, and androgenized females using a paradigm from our previous study (16). Briefly, 4 Silastic capsules containing estradiol were implanted s.c. in the axillary region of each lamb to provide high physiologic concentrations of the hormone (approximately $12 \mathrm{pg} / \mathrm{ml}$ ). Each Silastic capsule (o.d. $0.46 \mathrm{~cm}$, i.d. $0.34 \mathrm{~cm}$; Dow Corning, Midland, MI, USA) contained a $30-\mathrm{mm}$ column of packed crystalline estradiol 17- $\beta$ (Sigma Chemical Co.) and was sealed with Silastic Adhesive Type A (Dow Corning). To prevent a postimplantation peak in steroid release, estradiol implants were preincubated in water overnight before insertion (25). Five weeks earlier, this paradigm was determined to be effective in inducing an LH surge in the same female lambs in the present experiment (17). In the current study, blood samples were collected beginning at about $7 \mathrm{~h}$ after the insertion of implants, using the procedure described below for the determination of patterns of GnRH and LH secretion.

\section{Portal surgery and blood collection}

When the lambs were approximately 42 weeks of age, a device designed for the collection of hypophyseal portal blood was installed into each lamb, 'using the technique described by Caraty et al. (18). The portal collection device was modified for use in the smaller lamb by reducing both the diameter of the collection cup which forms a seal around the portal blood vessels, and the overall length (19). One week after installation of the device, blood was collected as described previously (18) from six lambs at a time; the lambs were kept unrestrained in separate stalls. In each stall, the lambs were free to behave normally, water and alfalfa hay were provided ad libitum. Each lamb was initially administered $25,000 \mathrm{U}$ heparin (i.v.) every half-hour for $2 \mathrm{~h}$. A maintenance dose of $16,000 \mathrm{U} / \mathrm{h}$ throughout the collection period was infused into a jugular vein via a peristaltic pump (Gilson Minipuls 3; Middleton, WI, USA). Portal vessels were lesioned by means of a stylette inserted into the upper guide tube of the collection device; the stylette was lowered a mm at a time by means of a custom-made threaded device (Turbine Tool and Gauge, Livonia, MI, USA) until adequate portal blood flow was established. Blood for the determination of GnRH was aspirated through the lower guide tube by a peristaltic pump. Portal blood was collected as hourly pools into chilled graduated cylinders containing $3 \mathrm{ml}$ of bacitracin $\left(3 \times 10^{-3} \mathrm{M}\right.$, Sigma) to reduce the degradation of GnRH. Jugular blood $(5 \mathrm{ml})$ for the determination of $\mathrm{LH}$ was collected as a single hourly sample through a jugular catheter. Collection continued until $48 \mathrm{~h}$ after steroid implant insertion. Blood samples were centrifuged, and plasma was separated and rapidly frozen within one hour of collection. Portal and jugular blood hematocrits were monitored every $3-4 \mathrm{~h}$ to check for possible contamination of the portal blood samples with cerebrospinal fluid, and to assess the health status of each lamb. After the collection period, each lamb was euthanized using a barbiturate overdose (Beuthanasia-D Special, Schering-Plough Animal Health Corp., Kenilworth, NJ, USA). The placement of the portal blood collection device and the position of the lesion on the face of the pituitary were verified. All procedures were approved by the Committee for the Use and Care of Animals at the University of Michigan.

$L H$ and GnRH radioimmunoassays

LH was measured in duplicate $25-200 \mu l$ aliquots of plasma using a modification $(44,45)$ of a radioimmunoassay developed by Niswender et al. (46). Assay sensitivity, defined as two standard deviations from maximum binding, averaged $0.62 \pm 0.03 \mathrm{ng} / \mathrm{ml}(\mathrm{n}=5$ assays) for $200 \mu \mathrm{l}$ of plasma, expressed relative to NIH-LH-S12. Intraassay coefficient of variation $(\mathrm{CV})$, determined from a serum pool that bound at $50 \%$, averaged $8.15 \%$; interassay $\mathrm{CV}$ averaged $9.12 \%$.

GnRH was measured using a previously described radioimmunoassay $(47,48)$, which was modified for the present study with the use of the antiserum BDS $4 / 85$, diluted at $1: 400,000$. Fig. 4 presents binding percentages of this antibody vs BDS 037 to a GnRH standard $(1.8 \mathrm{ng} / \mathrm{ml})$ as

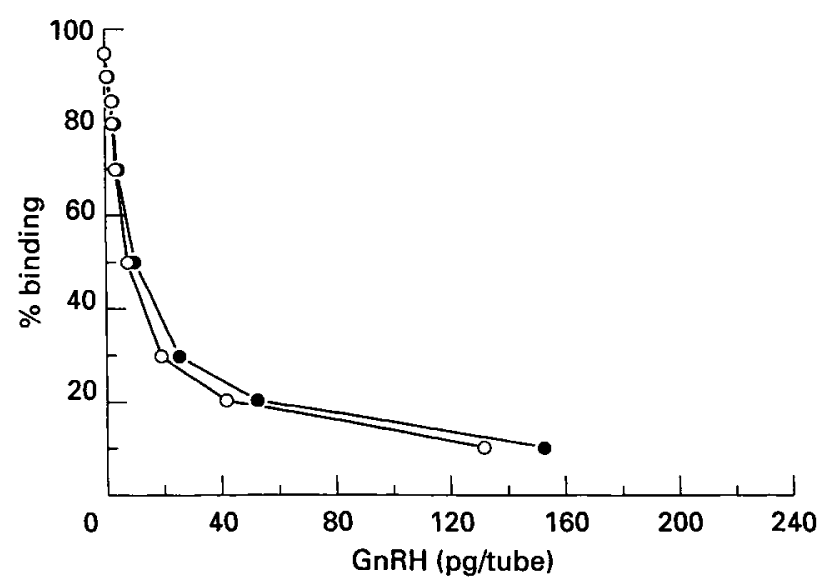

FIG. 4. Binding percentages of GnRH antibody BDS 4/85 vs BDS 037 against a GnRH standard $(1.8 \mathrm{ng} / \mathrm{ml})$. BDS 4/85; O BDS 037 .

reported previously $(47,48)$. Briefly, portal blood samples $(750 \mu \mathrm{l}$, containing $\sim 600 \mu \mathrm{l}$ of plasma and $\sim 150 \mu$ of bacitracin) were extracted with methanol and evaporated to dryness, then reconstituted in assay

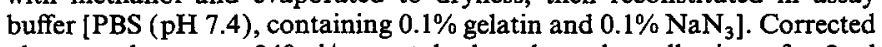
plasma volume was $240 \mu \mathrm{l} /$ assay tube based on the collection of a $2 \mathrm{ml}$ portal blood sample with $0.5 \mathrm{ml}$ bacitracin. Procedural blanks within assays consisted of extracts of peripheral samples taken into bacitracin $(750 \mu \mathrm{l})$, bacitracin alone $(750 \mu \mathrm{l})$, assay buffer $(750 \mu \mathrm{l})$, and methanol $(2 \mathrm{ml})$. Extracts were assayed in duplicate $50 \mu \mathrm{l}$ aliquots, with all samples for each lamb measured in a single assay. Intraassay variation, based on the median variance ratio of assay replicates (49), averaged $0.06 \pm 0.01$. Assay sensitivity averaged $0.22 \pm 0.02 \mathrm{pg} / \mathrm{tube}(\mathrm{n}=4$ assays); displacement of $\left[{ }^{125} \mathrm{I}\right] \mathrm{GnRH}$ to $50 \%$ of the buffer controls was $6.96 \pm 0.73 \mathrm{pg} /$ tube. To determine cross reactivity with peripheral plasma substances, $750 \mu]$ aliquots of 4 jugular plasma samples collected from each lamb at the beginning, middle, and end of the sampling series were processed as portal samples (i.e. extracted in methanol and reconstituted) and assayed simultaneously with the portal samples. There was minor activity detected in peripheral plasma of $75 \%$ of the lambs; in those, the average values for jugular samples $(0.57 \pm 0.11 \mathrm{pg} / \mathrm{tube} ; \mathrm{n}=4$ assays) were above the assay sensitivity $(0.22 \pm 0.02 \mathrm{pg} /$ tube). The remaining $25 \%$ of the lambs did not exhibit any activity, thus the amount of activity differed between animals. The activity was not associated with the degree of heparinization nor the presence of bacitracin. Because there was no positive association of the level of activity with GnRH values in portal blood (high vs low), it is unlikely that the substance is GnRH. Therefore, to calculate the final value for $\mathrm{GnRH}$, an average value for the interfering plasma activity was determined from the four estimates for each animal, and this plasma blank was subtracted from the measured value for $\mathrm{GnRH}$.

The recovery rate was determined by adding a known quantity of $\mathrm{GnRH}(5 \mathrm{pg})$ to jugular plasma samples and then by assaying them at the same dilutions as plasma samples without GnRH. The recovery rates were usually $100 \%$; if not, plasma concentrations were corrected for losses. GnRH concentrations are expressed as rate of collection $(\mathrm{pg} / \mathrm{min})$ rather than concentration $(\mathrm{pg} / \mathrm{ml}$ ) as justified previously (47). As discussed, this method corrects for three factors: first, for nonportal blood leaking into the collection area; second, for changes in sample collection rate that are independent of a change in GnRH secretion rate; third, for contamination of portal blood with cerebrospinal fluid (negligible in the present study).

\section{Data analysis}

GnRH and LH surges induced by increased estradiol concentrations were identified using the following method. Baseline amounts of GnRH and LH were determined from the average of the first three-hourly values obtained for each lamb. This average represented the minimum $\mathrm{GnRH} / \mathrm{LH}$ concentration during inhibition by estradiol. Then, a surge was identified if amounts of GnRH or LH reached or exceeded three times the average baseline concentration, and remained elevated for at 
632 Sexual differentiation of the GnRH surge

least $6 \mathrm{~h}$. The amplitude of the GnRH and $\mathrm{LH}$ surges were determined by subtracting the average pre-surge baseline amount from the peak value

The incidence of GnRH and LH surges were compared among groups using Fisher's Exact test for $2 \times 2$ tables. Characteristics of the GnRH and LH surges (onset, duration, time to peak concentration) in the females were compared using a two-tailed Student's i-test, and MannWhitney $U$ test. The end of the surge was defined as the first sample that decreased to below three times the average baseline concentration; this also determined the duration of the surge. If the last sample remained elevated, duration was not determined. It was not possible to make statistical comparisons of surge characteristics between groups because only 1 male and 1 androgenized female exhibited GnRH and LH surges. Values below assay sensitivity were assigned the limit of sensitivity of the assay.

\section{Acknowledgements}

We are indebted to Glenn W. and Jeanette M. Manning (Hubbard Lake, MI, USA) for providing the high quality lambs for this study, Douglas D. Doop for his expert technical advice and assistance. We are especially grateful to Dr Fred J. Karsch for assistance with establishing the portal collection procedure in the lamb. For their help in conducting the study, we also thank Dr Rhonda Maney, Dr David C. Bucholtz, Meredith L. Saillant, and Vikas Mehta. Important contributions were made by members of various Core Facilities of the Center for the Study of Reproduction (NIH P30 HD 18258): Gary R. McCalla of the Sheep Research Core Facility for conscientious animal care; Michael R. Muha of the Administrative Core Facility for administrative and computer assistance; the Assays and Reagents Core Facility for standardization of hormone radioimmunoassay reagents. We gratefully acknowledge Dr Gordon D. Niswender, Colorado State University, and Dr Leo E. Reichert, Jr., Albany Medical College for providing the reagents used in the LH assay, also Dr Alain Caraty, Station de Physiologie de la Reproduction, INRA, Nouzilly France for reagents in the GnRH assay. Finally, for the materials and labor donated for the manufacture of the portal vessel lesioning device, we thank Turbine Tool and Gauge Corporation, Livonia, MI.

Supported by NRI Competitive Grants Program/USDA 92-37203-7921, NIH F32 HD07642 (to GED), USDA 90-37240-5507 (to Fred J. Karsch), NIH P30 HD 18258 (Center for the Study of Reproduction), and the Office of the Vice-President for Research at the University of Michigan.

Accepted 24 April 1996

\section{References}

1 Mallampati RS, Johnson DC. Serum and pituitary prolactin, LH and FSH in androgenized female and normal male rats treated with various doses of estradiol benzoate. Neuroendocrinology 1973; 11: $46-56$.

2 Brown-Grant K. Steroid hormone administration and gonadotropin secretion in the gonadectomized rat. J Endocrinol 1974; 62: 319-332.

3 Terasawa E, Rodriguez JS, Bridson WE, Wiegand SJ. Factors influencing the positive feedback action of estrogen upon the luteinizing hormone surge in the ovariectomized guinea pig. Endocrinology 1979; 104: 680-686.

4 Norman RL, Spies HG. Neural control of the estrogen-dependent twenty-four hour periodicity of LH release in the golden hamster. Endocrinology 1974; 95: 1367-1372.

5 Karsch FJ, Foster DL. Sexual differentiation of the mechanism controlling the preovulatory discharge of luteinizing hormone in sheep. Endocrinology 1975; 97: 373-379.

6 MacLusky NJ, Naftolin F. Sexual differentiation of the central nervous system. Science 1981; 211: 1294-1303.

7 Gorski RA. Localization of the neural control of luteinization in the feminine male rat (FALE). Anat Rec 1967; 157: 63-69.

8 Yazaki I. Further studies on endocrine activity of subcutaneous ovarian grafts in male rats by daily examination of smears from vaginal grafts. Annot Zool Jap 1960; 33: 217-225.
9 Gorski RA, Wagner JW. Gonadal activity and sexual differentiation of the hypothalamus. Endocrinology 1965; 76: 226-239.

10 Barraclough CA. Production of anovulatory, sterile rats by single injections of testosterone propionate. Endocrinology 1961; 68: 62-67.

11 Barraclough CA, Gorski RA. Evidence that the hypothalamus is responsible for androgen-induced sterility in the female rat. Endocrinology 1961; 68: 68-79.

12 Short RV. Sexual differentiation of the brain of the sheep. INSERM 1974; 32: 121-142.

13 Clarke IJ, Scaramuzzi RJ, Short RV. Sexual differentiation of the brain: Endocrine and behavioural responses of androgenized ewes to estrogen. $J$ Endocrinol 1976; 71: 175-176.

14 Clarke IJ, Scaramuzzi RJ. Sexual behaviour and LH secretion in spayed androgenized ewes after a single injection of testosterone or estradiol. $J$ Reprod Fert 1978; 52: 313-320.

15 Wood RI, Ebling FJP, I'Anson H, Bucholtz DC, Yellon SM, Foster DL. Prenatal androgens time neuroendocrine sexual maturation. Endocrinology 1991; 128: 2457-2468.

16 Wood RI, Foster DL. Prenatal androgens and the timing of seasonal reproductive transitions in sheep. Biol Reprod 1992; 47: 389-396.

17 Wood RI, Mehta V, Herbosa CG, Foster DL. Prenatal testosterone differentially masculinizes tonic and surge luteinizing hormone secretion in the developing sheep. Neuroendocrinology 1995; 62: 238-247.

18 Caraty A, Locatelli A, Moenter SM, Karsch FJ. Sampling of hypophyseal portal blood of conscious sheep for direct monitoring of hypothalamic neurosecretory substances. In: Levine JE, ed. Pulsatility in Neuroendocrine Systems, Methods in Neuroscience, San Diego: Academic Press, 1994: vol. 20, 162-183.

19 Foster DL, Manning JM, Herbosa CG, Karsch FJ. Pattern of GnRH secretion in the agonadal female lamb. Program of the Ninth International Congress of Endocrinology, Nice, France: 1992: 414 (Abstr.).

20 Herbosa CG, Wood RI, Foster DL. Prenatal androgens modify the reproductive response to photoperiod in the developing sheep. Biol Reprod 1995; 52: 163-169.

21 Taleisnik S, Caligaris L; Astrada A. Sex differences in hypothalamohypophyseal function. In: Sawyer $\mathrm{CH}$, Gorski RA, eds. Steroid Hormones and Brain Function, University of Berkeley Press, Berkeley: 1971: 171-184.

22 Brown-Grant K, Sherwood MR. The 'early androgen syndrome' in the guinea pig. $J$ Endocrinol 1971; 49: 277-291.

23 Swanson $\mathrm{HH}$. Effects of castration at birth in hamsters of both sexes on luteinization of ovarian implants, oestrous cycles and sexual behavior. $J$ Reprod Fertil 1970; 21: 183-186.

24 Alleva FR, Alleva JJ, Umberger EJ. Effect of a single prepubertal injection of testosterone propionate on later reproductive functions of the female golden hamster. Endocrinology 1969; 85: 312-318.

25 Karsch FJ, Dierschke DJ, Weick RF, Yamaji T, Hotchkiss J, Knobil E. Positive and negative feedback control by estrogen of luteinizing hormone secretion in the rhesus monkey. Endocrinology 1973; 92: 799-804.

26 Karsch FJ, Dierschke DJ, Knobil E. Sexual differentiation of pituitary function: Apparent difference between primates and rodents. Science 1973; 179: 484-486.

27 Steiner RA, Clifton DK, Spies HG, Resko JA. Sexual differentiation and feedback control of luteinizing hormone secretion in the rhesus monkey. Biol Reprod 1976; 15: 206-212.

28 Steiner RA, Schiller HS, Barber J, Gale CC. Luteinizing hormone regulation in the monkey (Macaca nemestrina): Failure of testosterone and dihydrotestosterone to block the estrogen-induced gonadotropin surge. Biol Reprod 1978; 19: 51-56.

29 Levine JE, Ramirez VD. Luteinizing hormone-releasing hormone release during the rat estrous cycle and after ovariectomy as estimated with push-pull cannulae. Endocrinology 1982; 111: 1439-1448.

30 Sarkar DK, Fink $G$. Effects of gonadal steroids on output of luteinizing hormone releasing factor into pituitary stalk blood in the female rat. $J$ Endocrinol 1979; 80: 303-313.

31 Sarkar DK, Chiappa SA, Fink G. Gonadotropin-releasing hormone surge in pro-oestrus rats. Nature 1976; 264: 461-463.

32 Pau KYF, Berria M, Hess DL, Spies HG. Preovulatory gonadotropin-releasing hormone surge in ovarian-intact rhesus macaques. Endocrinology 1993; 133: 1650-1656.

33 Xia L, Van Vugt D, Alston EJ, Luckhaus J, Ferin M. A surge of 
gonadotropin-releasing hormone accompanies the estradiol-induced gonadotropin surge in the rhesus monkey. Endocrinology 1992; 131: 2812-2820.

34 Wood RI, Kim S-J, Foster DL. Prenatal androgens defeminize activation of GnRH neurons in response to estradiol stimulation. $J$ Neuroendocrinol 1996; 8: 617-625.

35 Wilson PR, Tarttelin MF. Studies of sexual differentiation in sheep II. Evidence of postnatal hypothalamic hypophysiotrophic depression of basal LH secretion following prenatal androgenization. Acta Endocrinologica 1978; 89: 190-195.

36 Kesner JS, Convey EM, Anderson CR. Evidence that estradiol induces the preovulatory $\mathrm{LH}$ surge in cattle by increasing pituitary sensitivity to LHRH and then increasing LHRH release. Endocrinology 1981; 108: 1386-1391.

37 Steiner RA, Clifton DK, Spies HG, Resko JA. Sexual differentiation and feedback control of luteinizing hormone secretion the rhesus monkey. Biol Reprod 1976; 15: 206-212.

38 Clarke IJ, Cummins JT. Direct pituitary effects of estrogen and progesterone on gonadotropin secretion in the ovariectomized ewe. Neuroendocrinology 1984; 39: 267-274.

39 Phillips DJ, Cummins JT, Clarke IJ. Effects of modifying gonadotrophin-releasing hormone input before and after the oestrogen-induced LH surge in ovariectomized ewes with hypothalamo-pituitary disconnection. $J$ Endocrinol 1990; 127: 223-233.

40 Wood RI, Newman SW, Lehman MN, Foster DL. GnRH neurons in the fetal lamb hypothalamus are similar in males and females. Neuroendocrinology 1992; 55: 427-433.

41 Witkin JW, Ferin M, Popilskis SJ, Silverman A-J. Effects of gonadal steroids on the ultrastructure of GnRH neurons in the rhesus monkey: Synaptic input and glial apposition. Endocrinology 1991 129: 1083-1092.

42 Clarke IJ, Scaramuzzi RJ, Short RV. Effects of testosterone implants in pregnant ewes on their female offspring. $J$ Embryol Exp Morph 1976; 36: 87-99.

43 Ebling FJP, Foster DL. Photoperiod requirements for puberty differ from those for the onset of the adult breeding season in the female sheep. J Reprod Fertil 1988; 84: 283-293.

44 Ebling FJP, Wood RI, Karsch FJ et al. Metabolic interfaces between growth and reproduction III. Central mechanisms controlling pulsatile luteinizing hormone secretion in the nutritionally growth-limited female lamb. Endocrinology 1990; 126: 2719-2727.

45 Hauger RL, Karsch FJ, Foster DL. A new concept for control of the estrous cycle of the ewe based upon temporal relationships between luteinizing hormone, estradiol, and progesterone and evidence that progesterone inhibits tonic LH secretion. Endocrinology 1977; 101: 807-817.

46 Niswender GD, Reichert $\mathrm{LE} \mathrm{Jr}$, Midgley $\mathrm{AR} \mathrm{Jr}$ et al. Radioimmunoassay for bovine and ovine luteinizing hormone. Endocrinology 1969; 84: 1166-1173.

47 Moenter SM, Caraty A, Karsch FJ. The estradiol-induced surge of gonadotropin-releasing hormone in the ewe. Endocrinology 1990; 127: $1375-1384$.

48 Caraty A, Locatelli A. Effect of time after castration on secretion of LHRH and LH in the ram. $J$ Reprod Fert 1988; 82: 263-269.

49 Duddleson WG, Midgley AR, Niswender GD. Computer program sequence for analysis and summary of radioimmunoassay data. Comput Biol Med Res 1972; 5: 205-217. 